\section{Effects of Low Relative Humidity and Illumination on Leaf Water Status of Cucumber Seedlings and Growth of Harvested Cuttings}

Toshio Shibuya, ${ }^{1}$ Ryoko Terakura, Yoshiaki Kitaya, and Makoto Kiyota Graduate School of Life and Environmental Science, Osaka Prefecture University, Gakuen-cho 1-1, Sakai, Osaka 599-8531, Japan

Additional index words. cutting propagation, leaf conductance, transpiration rate, vapor pressure deficit, water potential, water stress

\begin{abstract}
Application of a low-relative-humidity treatment (LHT) to seedlings can reduce water stress on cuttings harvested from the seedlings, after the cuttings are planted. Effects of illumination during LHT and LHT duration on leaf water potential and leaf conductance in cucumber (Cucumis sativus $\mathrm{L}$.) seedlings used as the model plant material and on growth of harvested cuttings were investigated to determine optimal LHT conditions. The seedlings received LHT for 12 or $24 \mathrm{~h}$ in a lighted or dark growth chamber at air temperatures of 28 to $31{ }^{\circ} \mathrm{C}$ and relative humidity of $12 \%$ to $25 \%$. Cuttings including a foliage leaf and two cotyledons were harvested by cutting the hypocotyl of the seedlings immediately after the treatment, and then the cuttings were planted in vermiculite medium. Four days after planting, the total fresh weight of the cuttings from seedlings that had received LHT in the lighted chamber was 2.2 times that of cuttings from seedlings that had not received LHT, whereas the total fresh weight of those that had received LHT in the dark increased by 1.3 to 1.8 times. Significant effects of illumination during LHT were also observed in the transpiration rate and growth of the cuttings, harvested following the treatment, after they were planted. By varying LHT duration, it was also found that leaf water potential and leaf conductance of the seedlings decreased as LHT duration increased up to $18 \mathrm{~h}$. Thus, illumination during LHT increased the growth of cuttings taken following the treatment, and optimal treatment duration of around $18 \mathrm{~h}$ was estimated from the seedlings' leaf conductance and leaf water potential.
\end{abstract}

Generally, cuttings are easily damaged by water stress immediately after they are planted, because their ability to absorb water is much less than that of the stock plants from which the cuttings came. Therefore, accurate environmental control of temperature, humidity, and light after planting is required to reduce water stress on cuttings (Hartmann et al., 2002; Macdonald, 1986). The response of cuttings or cut flowers to environmental stress also depends on the environment of the stock plants before the cuttings or cut flowers are taken (Mortensen, 2000; Mortensen and Fjeld, 1995, 1998; Terakura et al., 2003). Therefore, the water stress on harvested cuttings after planting can be reduced by modifying the environment of the stock plants prior to the harvest as well as by controlling the environment of the cuttings after planting.

Previously, we reported that a low-relativehumidity treatment (LHT) applied for $24 \mathrm{~h}$ to cucumber seedlings reduced water stress on the harvested cuttings after planting because of the changed transpiration characteristics of the seedlings (Shibuya et al., 2003). In the

Received for publication 28 Sept. 2005. Accepted for publication 14 Dec. 2005. This study was partially supported by the Ministry of Education, Science, Sports and Culture of Japan, Grant-in-Aid for Young Scientists (A), 15688007, 2003-2005.

${ }^{1}$ To whom reprint requests should be addressed; e-mail shibuya@envi.osakafu-u.ac.jp.
1970) because they show relatively high leaf conductance and sensitively respond to environmental changes.

\section{Materials and Methods}

Experiment 1. Cucumber (Cucumis sativus L. 'Hokushin') seedlings were grown in a growth chamber under artificial light for $7 \mathrm{~d}$ after cotyledon expansion. The growth conditions were (light and dark) air temperature, 29 to 30 and $24^{\circ} \mathrm{C}$, relative humidity, $75 \%$ to $85 \%$ and $85 \%$ to $90 \%$, and vapor pressure deficit, 0.6 to 1.1 and 0.3 to $0.4 \mathrm{kPa}$. The air current speed was $0.1 \mathrm{~m} \cdot \mathrm{s}^{-1}$, and the photosynthetic photonflux (PPF) was $200 \mu \mathrm{mol} \cdot \mathrm{m}^{-2} \cdot \mathrm{s}^{-1}$ during a photoperiod of $12 \mathrm{~h} \cdot \mathrm{d}^{-1}$. White fluorescent lamps were used for illumination. The seedlings were grown in plastic pots $(\Phi, 60 \mathrm{~mm}$; height, $55 \mathrm{~mm}$ ) with vermiculite medium. Nutrient solution (A-type recipe of Otsuka House Solution, diluted by 1/2, Otsuka Chemical Co., Ltd., Japan) was supplied from the bottom of the pot as necessary.

LHT was applied to the seedlings growing in lighted or unlit chambers for 12 or $24 \mathrm{~h}, 7$ d after expansion of the cotyledons (Fig. 1). Five samples were used for each treatment. Another five seedlings were left in the growth chamber without LHT as a control. Two closed chambers capable of generating low-relativehumidity conditions (Shibuya et al., 2003) were used for the LHT. The growth room of one chamber received continuous illumination from white fluorescent lamps at a PPF of 200 $\mu \mathrm{mol} \cdot \mathrm{m}^{-2} \cdot \mathrm{s}^{-1}$, and the other chamber was kept dark. In both chambers, the air temperature was 28 to $31{ }^{\circ} \mathrm{C}$, the relative humidity was $12 \%$ to $25 \%$, the vapor pressure deficit was 2.8 to 4.0 $\mathrm{kPa}$, and the air current speed was 0.1 to 0.2 $\mathrm{m} \cdot \mathrm{s}^{-1}$. LHT for $24 \mathrm{~h}$ was begun $6 \mathrm{~h}$ after the beginning of the photoperiod, and LHT for $12 \mathrm{~h}$ was begun $18 \mathrm{~h}$ after the beginning of the photoperiod. The starting time of the LHT was different for the two treatment durations so that the cuttings would be planted at the same time, thus allowing their growth after planting to be accurately compared. Nutrient solution was supplied from the bottom of the pot at the start of the treatment and again $12 \mathrm{~h}$ later. The surface of the medium was covered with a plastic film to prevent evaporation. The transpiration rate of the seedlings was determined by measuring the weight of each pot with seedling and medium at the start and end of the treatment.

Each cutting, including a foliage leaf and two cotyledons, was harvested by cutting the hypocotyl of the seedling $20 \mathrm{~mm}$ below the cotyledons immediately after LHT. The cuttings were planted in plastic pots containing vermiculite medium to a depth of $15 \mathrm{~mm}$ above the cut end and then grown in a growth chamber for $6 \mathrm{~d}$. Water and nutrient solution (A-type recipe of Otsuka House Solution, diluted to $1 / 4$ strength) were supplied from the bottom of the pot on days 0 to 3 and 3-6 after planting, respectively. The growth conditions after planting were air temperature 25 to $28^{\circ} \mathrm{C}$, relative humidity $60 \%$ to $90 \%$, vapor pressure deficit 0.3 to $1.5 \mathrm{kPa}$, and air current speed 0.1 
Growing in high RH with lighting cycle of $12 \mathrm{~h} \cdot \mathrm{d}^{-1}$

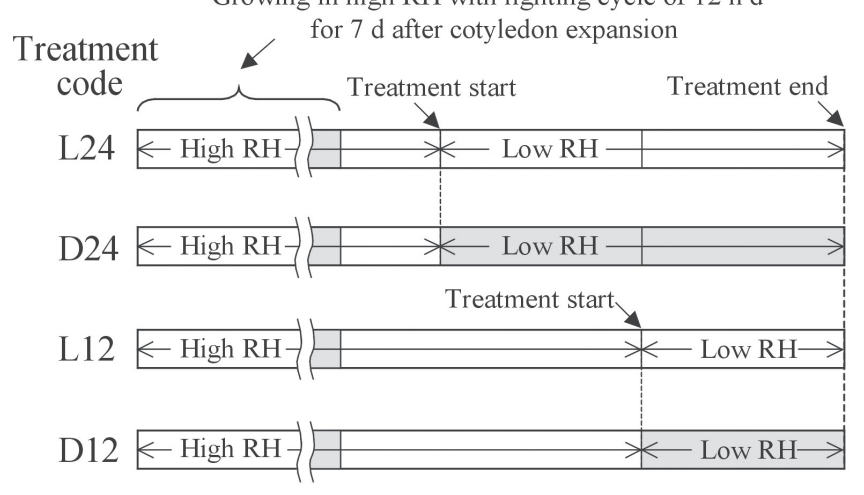

Control

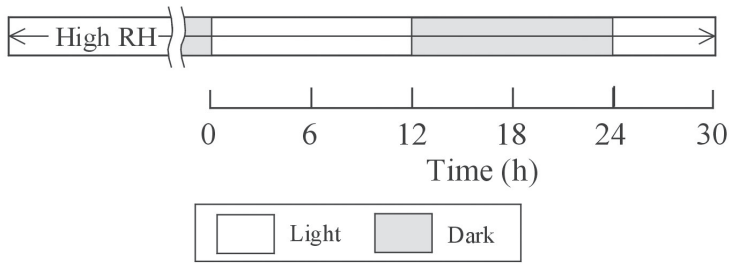

Fig. 1. Diagram of the relative humidity and illumination for each treatment in Expt. 1.

$\mathrm{m} \cdot \mathrm{s}^{-1}$. Continuous illumination was provided with white fluorescent lamps at a PPF of 100 $\mu \mathrm{mol} \cdot \mathrm{m}^{-2} \cdot \mathrm{s}^{-1}$.

Fresh and dry weights of the seedlings were measured at the start and end of treatment. Percent dry matter of the seedlings was determined by dividing the dry weight by the fresh weight. Fresh weight and leaf number, including the cotyledons, of the cuttings were measured before and $6 \mathrm{~d}$ after planting. Survival rate of leaves was determined by dividing the number of surviving leaves by the total number of leaves (i.e., the sum of surviving and withered leaves) $6 \mathrm{~d}$ after planting. A leaf with browning and necrosis over $50 \%$ of its area was considered to be withered. Effects of illumination during LHT were analyzed with analysis of variance (ANOVA) at $p=$ 0.01 and 0.05 .

Experiment 2. Cucumber seedlings were grown in a growth chamber for $7 \mathrm{~d}$ after cotyledon expansion at a (light and dark) air temperature of 30 and $28^{\circ} \mathrm{C}$, relative humidity of $80 \%$ and $90 \%$, and vapor pressure deficit of 1.5 and $0.3 \mathrm{kPa}$. PPF was $200 \mu \mathrm{mol} \cdot \mathrm{m}^{-2} \cdot \mathrm{s}^{-1}$, with a photoperiod of $12 \mathrm{~h} \cdot \mathrm{d}^{-1}$, and the air current speed was $0.2 \mathrm{~m} \cdot \mathrm{s}^{-1}$. The seedlings were transferred to a low-humidity chamber (LHS-200L, Ikeya Co., Ltd., Japan) 3, 9, 15, 19 , or $23 \mathrm{~h}$ after the start of a photoperiod, and they received LHT for $24,18,12,8$, or $4 \mathrm{~h}$, respectively (Fig. 2). In this way, all the treatments were finished $27 \mathrm{~h}$ after the start of the photoperiod. Seven samples were used for each treatment. Another seven seedlings were left in the growth chamber without LHT as a control. During LHT, air temperature was 30 to $31{ }^{\circ} \mathrm{C}$, relative humidity $14 \%$ to $20 \%$, vapor pressure deficit 3.4 to $3.9 \mathrm{kPa}$, and air current speed $0.2 \mathrm{~m} \cdot \mathrm{s}^{-1}$. Continuous illumination was provided with white fluorescent lamps at a PPF of $200 \mu \mathrm{mol} \cdot \mathrm{m}^{-2} \cdot \mathrm{s}^{-1}$. Nutrient solution was supplied from the bottom of the pot continuously

$T=\frac{W t_{1}-W t_{2}}{t_{2}-t_{1}}$
Growing in high RH with lighting cycle of $12 \mathrm{~h} \cdot \mathrm{d}^{-1}$

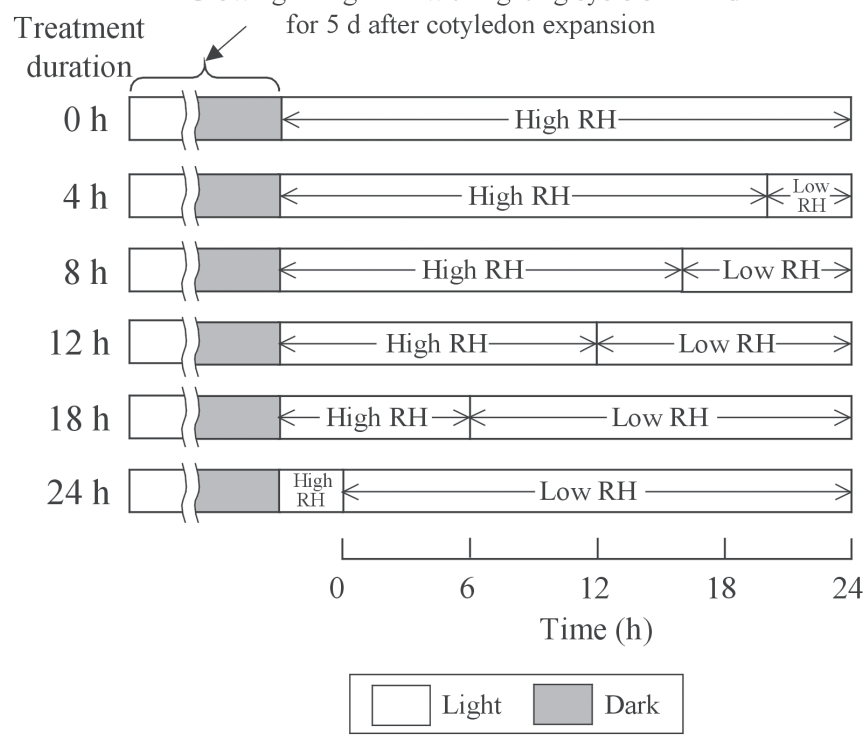

during LHT by setting the pots in the nutrient solution to a depth of $5 \mathrm{~mm}$.

Leaf conductance of the first foliage leaf was measured with a steady-state porometer (LI-1600; LI-COR Inc., Lincoln, Neb.) at the end of treatment. Cuttings containing a foliage leaf and two cotyledons were harvested as in Expt. 1. The cuttings were planted in a glass vessel $(\Phi, 30 \mathrm{~mm}$; height, $65 \mathrm{~mm})$ in a nutrient solution (A-type recipe, Otsuka house solution, diluted to $1 / 4$ strength) to a depth of 15 $\mathrm{mm}$ above the cut end and then grown in the growth chamber for $4 \mathrm{~d}$. The upper surface of each vessel was covered with a plastic film to prevent evaporation of the solution. The growth conditions after planting were air temperature 25 to $29{ }^{\circ} \mathrm{C}$, relative humidity $65 \%$ to $90 \%$, vapor pressure deficit 0.3 to $1.4 \mathrm{kPa}$, and air current speed $0.1 \mathrm{~m} \cdot \mathrm{s}^{-1}$. Continuous illumination was provided with white fluorescent lamps at a PPF of $100 \mu \mathrm{mol} \cdot \mathrm{m}^{-2} \cdot \mathrm{s}^{-1}$. Water absorption and transpiration rates of the cuttings were determined from the weight of the cutting and that of the vessel containing the cutting and nutrient solution before and $17 \mathrm{~h}$ after planting by the following equations:

where $T$ is the transpiration rate $\left(\right.$ as $\mathrm{H}_{2} \mathrm{O} g \cdot \mathrm{h}^{-1}$ per cutting), and $W t_{1}$ and $W t_{2}$ are the weights of the vessel containing the nutrient solu-

Fig. 2. Diagram of the low-relative-humidity treatments with different durations in Expt. 2.

tion at time (h) $t_{1}$ and $t_{2}$, respectively $\left(t_{1}<t_{2}\right)$ (g/vessel).

$$
A=T-\frac{W c_{1}-W c_{2}}{t_{2}-t_{1}}
$$

where $A$ is the water absorption rate $\left(\right.$ as $\mathrm{H}_{2} \mathrm{O}$ $\mathrm{g} \cdot \mathrm{h}^{-1} /$ cutting), and $W c_{1}$ and $W c_{2}$ are the weights of the cutting at time (h) $t_{1}$ and $t_{2}$, respectively $\left(t_{1}<t_{2}\right)(\mathrm{g} /$ cutting $)$.

Fresh and dry weights of seedlings were measured at the start and end of treatment. Percent dry matter of the seedlings, and fresh weight, number of leaves, and leaf survival rate of the cuttings $4 \mathrm{~d}$ after planting were determined as in Expt. 1.

Experiment 3. Cucumber seedlings were grown by the same method as in experiment 1 for $7 \mathrm{~d}$ after cotyledon expansion at an air temperature of $29^{\circ} \mathrm{C}$, a relative humidity of $90 \%$, a vapor pressure deficit of $0.4 \mathrm{kPa}$, a PPF of $200 \mu \mathrm{mol} \cdot \mathrm{m}^{-2} \cdot \mathrm{s}^{-1}$, a photoperiod of 12 $\mathrm{h} \cdot \mathrm{d}^{-1}$, and an air current speed of $0.1 \mathrm{~m} \cdot \mathrm{s}^{-1}$. The seedlings were transferred to the lowhumidity chamber, and then LHT was applied under the same conditions as in Expt. 2. Leaf conductance and leaf water potential of the first foliage leaf of five seedlings were measured with a steady-state porometer and a dew-point potential meter(WP4T, Decagon Devices, Inc., Pullman, Wash.), respectively, 3, 6, 12, 18,

Table 1. Fresh weight, dry weight, and percent dry $\operatorname{matter}^{z}$ of cucumber seedlings after low-relative-humidity treatment (Expt. 1). For treatment codes, see Fig. 1.

\begin{tabular}{lccc}
\hline $\begin{array}{l}\text { Treatment } \\
\text { code }\end{array}$ & $\begin{array}{c}\text { Shoot } \\
\text { fresh wt } \\
\text { (g/plant) }\end{array}$ & $\begin{array}{c}\text { Shoot } \\
\text { dry wt } \\
\text { (mg/plant) }\end{array}$ & $\begin{array}{c}\text { Percent } \\
\text { dry } \\
\text { matter }\end{array}$ \\
\hline Before treatment & $1.25 \pm 0.05$ & $98 \pm 4$ & $7.9 \pm 0.1$ \\
L24 & $1.50 \pm 0.05$ & $142 \pm 4$ & $9.5 \pm 0.1$ \\
L12 & $1.53 \pm 0.07$ & $140 \pm 5$ & $9.2 \pm 0.2$ \\
D24 & $1.49 \pm 0.09$ & $88 \pm 6$ & $5.9 \pm 0.3$ \\
D12 & $1.43 \pm 0.06$ & $101 \pm 4$ & $7.1 \pm 0.1$ \\
Control & $1.60 \pm 0.08$ & $128 \pm 6$ & $8.0 \pm 0.0$ \\
ANOVA & NS & $* *$ & $* *$ \\
LSD (0.05) & 0.21 & 0.15 & 0.5 \\
Significance of illumination & NS & $* *$ & $* *$ \\
\hline
\end{tabular}

${ }^{\mathrm{z}}$ Means \pm standard errors are shown $(n=5)$.

NS, ${ }^{* *}$ Nonsignificant and significant at $p \leq 0.01$, respectively, by ANOVA. 
Table 2. Transpiration rate ${ }^{z}$ during the low-relativehumidity treatment in the light or dark and for different photoperiods (Expt. 1). For treatment codes, see Fig. 1.

\begin{tabular}{lc}
\hline $\begin{array}{l}\text { Treatment } \\
\text { code }\end{array}$ & $\begin{array}{c}\text { Transpiration rate } \\
\text { (as } \mathrm{H}_{2} \mathrm{O} \mathrm{g} \cdot \mathrm{h}^{-1} / \text { seedling) }\end{array}$ \\
\hline L24 & $1.56 \pm 0.03$ \\
L12 & $1.55 \pm 0.09$ \\
D24 & $0.95 \pm 0.02$ \\
D12 & $1.29 \pm 0.17$ \\
ANOVA & $* *$ \\
LSD (0.05) & 0.30 \\
Significance of illumination & $* *$ \\
\hline
\end{tabular}

${ }^{\text {zMeans }} \pm$ standard errors $(n=5)$.

${ }^{* *}$ Significant at $p \leq 0.01$ by ANOVA.

and $24 \mathrm{~h}$ after starting the treatment. The leaf water potential was measured according to the manufacturer's recommendations (Decagon Device Inc., 1999).

\section{Results and Discussion}

Experiment 1. The shoot dry weight of cucumber seedlings that received LHT in the light (L24 or L12) was significantly larger immediately after the treatments than that of those that received LHT in the dark (D24 or D12) or that of controls (Table 1). Transpiration rates of seedlings receiving LHT in the light (L24 or L12) were 1.2 to 1.6 times those of seedlings receiving LHT in the dark (D24 or D12) (Table 2). Percent dry matter of the seedlings that received LHT in the light (L24 or L12) was significantly larger than that of controls, whereas that of the seedlings receiving LHT in the dark (D24 or D12) was lower (Table 1). Significant effects of illumination during LHT were observed in the dry weights and percent dry matter of seedlings (Table 1), and in the transpiration rates of the seedlings during the treatment (Table 2). The lower values for seedlings that received LHT in the dark can probably be attributed to larger consumption of dry matter by respiration in the dark. Therefore, LHT given in the dark is not a practical means of preventing a reduction in the seedlings' dry matter content.

Four days after planting, the total fresh weight of cuttings from seedlings that received LHT (L24 or L12) in a lighted chamber was

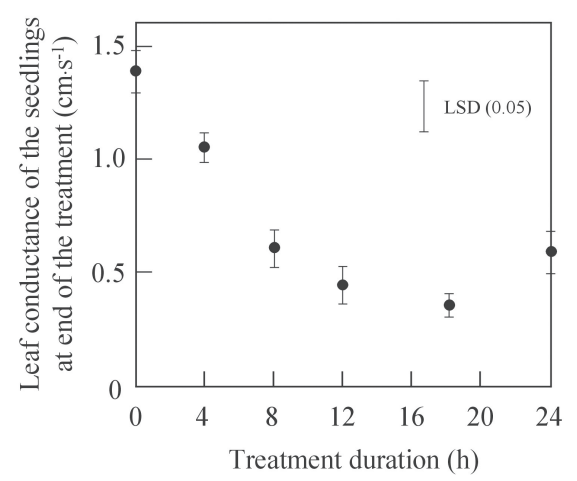

Fig. 3. Effects of the duration of the low-relativehumidity treatment on leaf conductance of cucumber seedlings at the end of the treatment (Expt. 2). Vertical bars indicate standard errors of the means $(n=7)$.

Table 3. Total, shoot, and root fresh weight, number of leaves, and survival rate of leaves of cucumber plants $^{z} 6 \mathrm{~d}$ after planting of cuttings taken following low-relative-humidity treatments in the light or dark and of different duration (Expt. 1). For treatment codes, see Fig. 1.

\begin{tabular}{lccccc}
\hline Treatment & $\begin{array}{c}\text { Total } \\
\text { fresh wt } \\
\text { code }\end{array}$ & $\begin{array}{c}\text { Shoot } \\
\text { fresh wt } \\
\text { (g/plant) }\end{array}$ & $\begin{array}{c}\text { Root } \\
\text { fresh wt } \\
\text { (g/plant) }\end{array}$ & $\begin{array}{c}\text { Total } \\
\text { leaves }^{\mathrm{yx}} \\
(\mathrm{no} .)\end{array}$ & $\begin{array}{c}\text { Survival rate } \\
\text { of leaves } \\
(\%)\end{array}$ \\
\hline L24 & $1.85 \pm 0.20$ & $1.55 \pm 0.16$ & $0.31 \pm 0.05$ & $4.4 \pm 0.2$ & $77 \pm 8$ \\
L12 & $1.90 \pm 0.16$ & $1.61 \pm 0.12$ & $0.29 \pm 0.04$ & $4.0 \pm 0.0$ & $85 \pm 10$ \\
D24 & $1.08 \pm 0.17$ & $0.96 \pm 0.13$ & $0.12 \pm 0.04$ & $4.0 \pm 0.0$ & $55 \pm 15$ \\
D12 & $1.56 \pm 0.10$ & $1.38 \pm 0.09$ & $0.19 \pm 0.02$ & $4.0 \pm 0.0$ & $70 \pm 15$ \\
Control & $0.85 \pm 0.17$ & $0.80 \pm 0.14$ & $0.06 \pm 0.03$ & $4.2 \pm 0.2$ & $34 \pm 10$ \\
ANOVA & $* *$ & $* *$ & $* *$ & NS & $*$ \\
LSD (0.05) & 0.48 & 0.38 & 0.11 & --- & 35 \\
Significance of illumination & $*$ & $* *$ & $* *$ & NS & NS \\
\hline
\end{tabular}

${ }^{\mathrm{z}}$ Means \pm standard errors are shown $(n=5)$.

y Includes the foliage leaves and the cotyledons.

'Includes the surviving and withered leaves.

NS,",***Nonsignificant and significant at $p \leq 0.05$ or 0.01 , respectively, by ANOVA.

2.2 times that of cuttings from seedlings that had not received LHT, whereas LHT given in the dark (D24 or D12) increased the total fresh weight by 1.3 to 1.8 times (Table 3 ). Significant effects of illumination during LHT were observed in the total, shoot, and root fresh weights of cuttings harvested following the treatment after they were planted (Table 3 ). The survival rate of leaves after treatments L 12 and L24 was $85 \%$ and $77 \%$, respectively, while it was only $33 \%$ in the controls. Previously, we inferred that during LHT, the water content of seedlings decreases through increased transpiration, thus reducing water stress in the cuttings by inhibiting transpiration in the cuttings immediately after they are planted (Shibuya et al., 2003). It follows, therefore, that illumination of the seedlings during LHT similarly reduces the water stress in their cuttings after planting by decreasing the water content of the seedlings
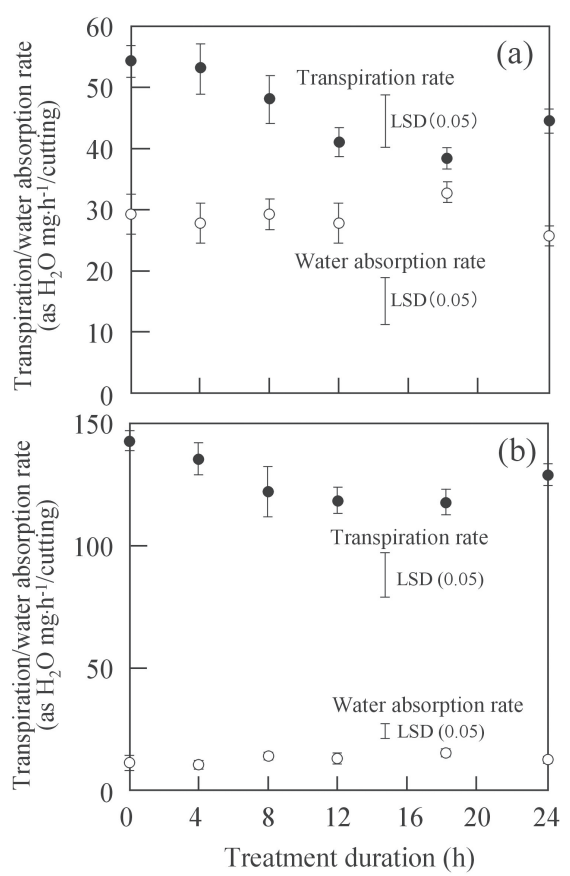

Fig. 4. Effects of the duration of the low-relativehumidity treatment on the transpiration and water absorption rates of cucumber cuttings, harvested following the treatment, at (a) $1 \mathrm{~h}$ and (b) $17 \mathrm{~h}$ after planting (Expt. 2). Vertical bars indicate standard errors of the means $(n=7)$. through an increase in the transpiration rate.

Experiment 2. Leaf conductance of seedlings at the end of the treatment (Fig. 3) and the transpiration rate of the cuttings after planting (Fig. 4) decreased as the treatment duration increased up to $18 \mathrm{~h}$, but these values were larger after $24 \mathrm{~h}$ of treatment than after $18 \mathrm{~h}$ of treatment. A similar relationship between LHT duration and leaf conductance was observed in an iterative experiment (data not shown). The increases in leaf conductance and transpiration rate increased at $24 \mathrm{~h}$ of treatment is probably caused by adaptation to the low relative humidity. The cuttings harvested from the seedlings with lower leaf conductance showed lower transpiration rates (Fig. 5) and higher growth after planting (Table 4). LHT duration had no significant effect on the water absorption rate of the cuttings after planting. The survival rate of leaves increased with increasing treatment duration. The cuttings from seedlings that had received LHT for $18 \mathrm{~h}$ showed leaf survival rate of $100 \%$ (Table 4 ). These results indicate that growth of the cuttings after planting increased as the duration of LHT became longer, up to the optimal LHT duration, which was around $18 \mathrm{~h}$ under the conditions of this experiment.

Experiment 3. The water potential of the cucumber seedlings and their leaf conductance began to decrease immediately after the start of LHT and plateaued at $18 \mathrm{~h}$ (Fig. 6). In this

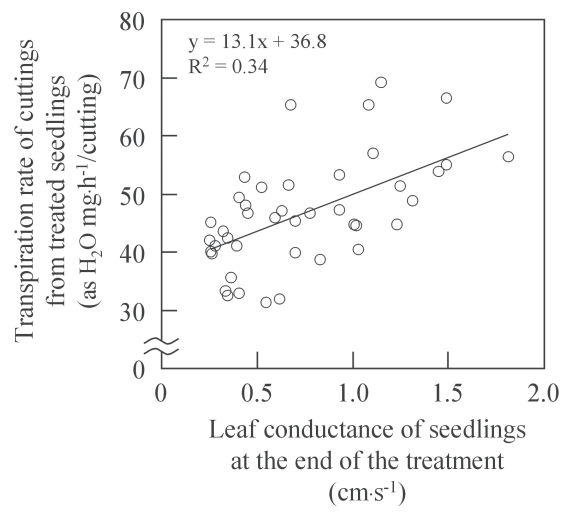

Fig. 5. Relationship between leaf conductance of the seedlings at the end of the low-relative-humidity treatment and transpiration rate of the cuttings, harvested following the treatment, after planting (Expt. 2). The transpiration rate was evaluated $17 \mathrm{~h}$ after the cuttings were planted. 
Table 4. Shoot fresh weight and number of leaves ${ }^{\mathrm{z}}$ of the cucumber cuttings at the end of low-relativehumidity treatments of different duration, and total, shoot, and root fresh weight, number of leaves, and survival rate of leaves of the cucumber plants $4 \mathrm{~d}$ after the cuttings, harvested following the treatment, were planted (Expt. 2).

\begin{tabular}{|c|c|c|c|c|c|c|}
\hline \multirow[b]{2}{*}{$\begin{array}{l}\text { Treatment } \\
\text { duration }(\mathrm{h})\end{array}$} & \multirow{2}{*}{$\begin{array}{c}\text { Before planting } \\
\text { Shoot } \\
\text { fresh wt } \\
\text { (g/cutting) }\end{array}$} & \multicolumn{5}{|c|}{$4 \mathrm{~d}$ after planting } \\
\hline & & $\begin{array}{c}\text { Total } \\
\text { fresh wt } \\
\text { (g/plant) }\end{array}$ & $\begin{array}{c}\text { Shoot } \\
\text { fresh wt } \\
\text { (g/plant) }\end{array}$ & $\begin{array}{c}\text { Root } \\
\text { fresh wt } \\
\text { (mg/plant) }\end{array}$ & $\begin{array}{c}\text { Total } \\
\text { leaves }^{\mathrm{yx}} \\
\text { (no.) }\end{array}$ & $\begin{array}{c}\text { Survival rate } \\
\text { of leaves } \\
(\%)\end{array}$ \\
\hline$\overline{0}$ & $1.34 \pm 0.05$ & $1.23 \pm 0.08$ & $1.20 \pm 0.08$ & $33 \pm 5$ & $4.0 \pm 0.0$ & $61 \pm 9$ \\
\hline 4 & $1.32 \pm 0.06$ & $1.25 \pm 0.07$ & $1.20 \pm 0.07$ & $50 \pm 6$ & $4.0 \pm 0.0$ & $54 \pm 9$ \\
\hline 8 & $1.29 \pm 0.05$ & $1.37 \pm 0.07$ & $1.32 \pm 0.07$ & $50 \pm 5$ & $4.0 \pm 0.0$ & $68 \pm 11$ \\
\hline 12 & $1.25 \pm 0.03$ & $1.47 \pm 0.07$ & $1.41 \pm 0.07$ & $59 \pm 6$ & $4.0 \pm 0.0$ & $93 \pm 7$ \\
\hline 18 & $1.24 \pm 0.04$ & $1.55 \pm 0.07$ & $1.48 \pm 0.06$ & $64 \pm 13$ & $4.0 \pm 0.0$ & $100 \pm 0$ \\
\hline 24 & $1.28 \pm 0.05$ & $1.41 \pm 0.08$ & $1.35 \pm 0.08$ & $56 \pm 4$ & $4.0 \pm 0.0$ & $86 \pm 5$ \\
\hline ANOVA & NS & $*$ & $*$ & NS & NS & $* *$ \\
\hline $\operatorname{LSD}(0.05)$ & --- & 0.21 & 0.20 & --- & --- & 22 \\
\hline
\end{tabular}

${ }^{2}$ Means \pm standard errors are shown $(n=7)$.

Includes the foliage leaves and cotyledons.

'Includes the surviving and withered leaves.

NS,, ${ }^{* * *}$ Nonsignificant and significant at $p \leq 0.05$ or 0.01 , respectively, by ANOVA.

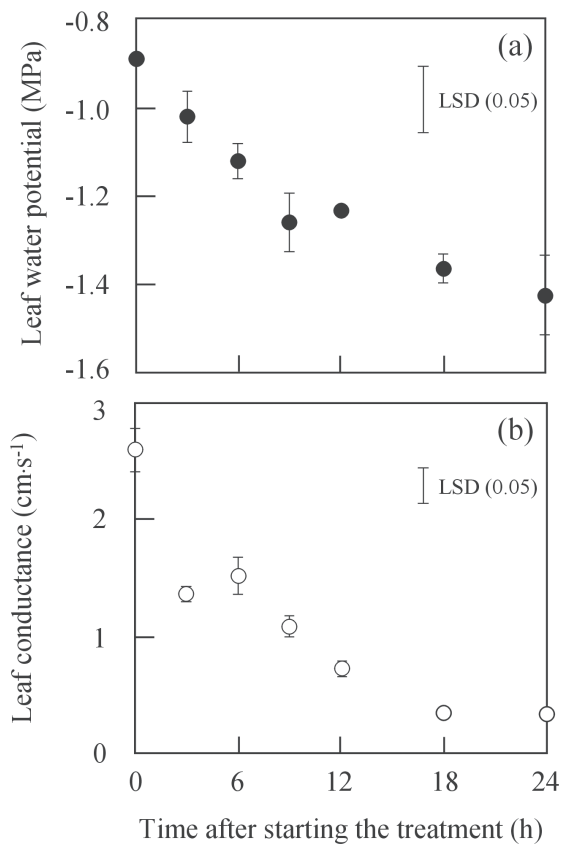

Fig. 6. Time courses of (a) leaf water potential and (b) leaf conductance of the seedlings after the start of the low-relative-humidity treatment (Expt. 3). Vertical bars indicate standard errors of the means $(n=5)$.

experiment, leaf conductance did not increase with treatments longer than $18 \mathrm{~h}$ such as occurred in Expt. 2, perhaps because of the higher initial relative humidity value in this experiment compared with those of Expt. 2, the treatment, after they were planted, apparently by enhancing the transpiration rate in the seedlings and thereby increasing their percent dry matter. Leaf water potential and leaf conductance of seedlings decreased during LHT with an increasing LHT duration up to $18 \mathrm{~h}$. These results indicate that illumination during LHT increase the growth of cuttings taken following the treatment, and the optimal treatment duration can be determined by changes in leaf conductance and leaf water potential during LHT. An optimal treatment duration of around $18 \mathrm{~h}$ was estimated from the seedlings' leaf conductance and leaf water potential in this study.

\section{Literature Cited}

Decagon Device Inc. 1999. Measurement of leaf water potential using the WP4. Decagon Device Inc., Pullman, Wash.

Hartmann, H.T., D.E. Kester, F.T. Davies,Jr., and R.L. Geneve. 2002. Plant propagation, p. 880.7th ed. Pearson Education, Upper Saddle River, N.J.

Kiyota, M. and K. Yabuki. 1975. Studies on the carbon dioxide environment for plant growth. VI. Effects of the carbon dioxide concentration on transpiration rate. (in Japanese text with English abstract) Environ. Control Biol. 13:151-158.

Macdonald, B. 1986. Practical woody plant propagation for nursery growers, p. 669. Timber Press, Portland, Ore.

Mortensen, L.M. and T. Fjeld. 1998. Effects of air humidity, lighting period and lamp type on growth and vase life of roses. Sci. Hor. 73:229-237.

Mortensen, L.M. 2000. Effect of air humidity on growth, flowering, keeping quality and relations of four short-day greenhouse species. Scientia Hort. 86:229-310.

Mortensen, L.M. and T. Fjeld. 1995. High air humidity reduces the keeping quality of rose. Acta Hort. 405:148-152.

or because of the different starting times of the treatments. Leaf conductance decreased with decreasing leaf water potential (Fig. 7). The results of Expts. 1 to 3 suggest the following process. LHT increased the transpiration rate of the seedlings, which caused the leaf water potential, and hence the leaf conductance, to decrease. The decreased leaf conductance of the seedlings caused the transpiration rate of the harvested cuttings to decrease immediately after planting. As a result, the water stress on the cuttings after planting was reduced, which allowed the growth of the cuttings to increase.

Application of the low-relative-humidity treatment to cucumber seedlings increased the growth of their cuttings, taken following
Shibuya, T., R. Terakura, and M. Kiyota, 2003. Effects of short-term treatment of air humidity on growth and transpiration characteristics of cucumber seedlings, and on growth of their cuttings (Japanese text with English abstract). Environ. Control Biol. 41:347-352.

Terakura, R., T. Shibuya, Y. Kitaya, and M. Kiyota. 2003. Effect of low relative humidity during tomato seedlings growth on quality of their cuttings under low-temperature and dim-light storage. (Japanese text with English abstract) Environ. Control Biol. 41:381-385.

Yabuki, K. and H. Miyagawa. 1970. Studies on the effect of wind speed upon the photosynthesis. II. The relation between wind speed and photosynthesis. (Japanese text with English abstract) J. Agr. Meteorol. 26:137-141. 